\title{
The Analysis of Operation and Management Situation in Chinese Professional Football Clubs
}

\author{
Yi Jia ${ }^{1}$ \\ ${ }^{1}$ Department of Physical Education, Qingdao University of Science and Technology, Qingdao, China \\ Correspondence: Yi Jia, Department of Physical Education, Qingdao University of Science and Technology, \\ Qingdao 266061, China. E-mail: jyqust@163.com
}

\author{
Received: January 11, $2012 \quad$ Accepted: February 14, $2012 \quad$ Published: May 1, 2012 \\ doi:10.5539/ass.v8n6p229 \\ URL: http://dx.doi.org/10.5539/ass.v8n6p229
}

\begin{abstract}
China football league has started the professional reforms since 1994, but so far the operation of many domestic professional football clubs has been more and more difficult. Only a few clubs can survive and the vast majority of club investors are changed frequently, including normal transferring, normal capital operation, even being dissolved because of hardships. As for the reasons, the club's management system, the low return rate on investment, and the poor operating performance can be drawn. The thesis, from the perspective of clubs' management system, will illustrate several reasons which influence the development of Chinese professional football clubs and put forward the feasible suggestions.
\end{abstract}

Keywords: professional football club, operation management, analysis

\section{Reason Analysis for Getting in Trouble of Chinese Professional Football Clubs}

\subsection{Property Rights Are Not Clear}

The professional football club is a substantive economic organization. The relation of property rights should be clear, which is the basic condition of normal operation. Because dislocation phenomenon appeared in current system of our national profession football, management rights restrict the ownership. Managers take both on the operation and management. System framework make managers monopolize sports social resources and rights are still not transferring.

But a large responsibility of "doing" professional sports was transferred to the professional football clubs through socialization. The investment structure of Chinese professional football clubs partly come from enterprise, the original state physical culture system inputs facilities, venue and sports teams, and personnel from cooperated parties. Because there is no harmonious and unified standard as for the property ownership and income distribution problems at the beginning of establishment of professional clubs, the property right is not clear so that the contradictions between state physical culture and investment enterprise have become more obvious. The intervention of the government's administrative and investment enterprise results in the management chaos. In the specific management process, the club managers make policies arbitrarily, go after the club's short-term interests and ignore its long-term health development.

\subsection{Lack Operation Management Talents of High Levels}

The professional football clubs, as a new type of enterprise, need a lot of operation management talents of high levels. They know the sports and football, and also need to have various professional knowledge including economy, law, and marketing etc. However, there are few operation management talents in Chinese professional football clubs, who are relatively low degree. Usually expertise in football business, who lacks relevant professional knowledge, so that it is impossible to lay out a clear development strategy, implement scientific rational marketing strategies, expand effective potential markets, and also it is impossible to design the scientific internal salary management system for enterprise, and so on. All of these are characterized by lower management level, which seriously restricts the positive healthy development of the Chinese professional football clubs. 


\subsection{Leading System of Professional Football Falling Behind}

At present football management department of all levels in China had done a lot of work in changing the function, but it is not completely done according to the professional football market demand, without getting rid of the means and methods of planned economy era. Lacking overall consideration and arrangement in the long-term planning, some local football association had the contradiction with the club because of the concept of the lag, the authority restriction and personal capacity constraints, plus lack of understanding for professional football, holding the original administrative power, even excessive administrative intervention in the club's management. The Chinese Football Association, the highest government agency and social organization, whose main function should be macro-control in the football development, should create a good external environment for the professional football development, rather than the management for the specific business. So, as for the Chinese Football Association and the local football association, the leadership department of the professional football, it is important that how to manage the club by laws, regulations and rules, the system and law means, and the necessary economic method and administrative methods so that it can play a proper role in the development of the Chinese professional football.

\subsection{Low Operating Efficiency}

From the management level, at present the club's market development ability is insufficient. So there are still no good and influenced products and competition, at the same time, the club extension products is less and less. Contrary to the club, other clubs take the unfair competition means. It is harmful for the club's management and market development by doing this, and it will cause the decrease of the whole market credibility of sports competition, so that the whole market is lost and falls into the passive situation.

From the management level, the current situation is it is rare for dozens of domestic football club to achieve a truly separation of ownership. From abroad, sports club is running completely according to the company, the way of joint stock system, and property rights and management right is separated. At present the general manager acted by investors or appointed representative is not uncommon. In fact there needs expertise who know both works and development and understand management professionals to run, therefore, the club goals and benefits will be better achieved.

\subsection{Substandard Football Industry Market}

A perfect market system should be various, orderly, and reasonable organization. To football market system in our country, market mainly concentrated in large and medium cities and a few economic developed area; level division is not rational; sports agent system of football market transactions between the buyer and the seller needs to be set up, sound and perfect; intermediary institution of high quality who Engaged in football market various business agency activities is not corresponded with the actual need and management and supervision system are to be improved and perfect; and also the market management development lacks dynamics. The data suggest that only a few teams in our country's football club soccer and medium armor team can make ends meet. in 1998, In the best of the professional football league, only 50\% of Team A group A and Team B (Liaoning team) can balance their own profits and losses and the rest of the 17 clubs have to rely on enterprise's investment to maintain the normal operation (24 teams). As the main body of the football industry, the income of domestic clubs is far backward to the foreign ones. At present the development of the market is less in our football club. Due to the dependence, market competition consciousness is bad. Clubs passively rely on football team grades completely and operate spontaneously. Not inputting human, material and energy in business development, or the input of advertising, sponsorship if possible, managers do not take the "small products" into account; fundamentally ignore the development and management of intangible assets.

\section{Reform Direction of Chinese Professional Football Clubs}

\subsection{The Introducing and Training of Advanced Management Talents Is Urgently Needed}

Professional football clubs in China should draw lessons from foreign experience; actively encourage domestic business management talents in all walks of life to participate in the football industry in the race to hiring talent, select senior management personnel suitable to the market demand. When necessary, foreign experienced managers should be introduced in mature market, through using the advanced management idea to promote the rapid development of the professional football clubs.

In the internal of professional football clubs, potential management talents should be trained and master related knowledge of football as soon as possible to improve the management level of the football club. The Chinese football association should be as a lead party, from the successful experience of coaches and referees entrust physical education experts, scholars to run football management training courses as soon as possible, and speed 
up the training of operation management talents. The content of teaching training can be mainly in foreign professional sports club business management mode and operation mechanism and the inspection abroad to participate in professional sports clubs, and the sports seminars of industry development and promotion.

\subsection{Implementing the Separate System between Government and Club Management}

The separate system between government and club management refers to cut the administrative subordinate relationship between them, clearly define their respective functions. The relationship between them is legal one, and government should manage the club in accordance with the law. The club is operated by law, and not subject to the government's direct intervention. The details are the following: the government is not directly involved in the club's specific affairs, and do to manage the club by the business institutions. The club really breaks the control of administrative organs and is able to arrange various activities according to the market demand; cuts off the funds dependent on government; the funds required for the club rely mainly on business accumulation and markets; cuts off the dependence on the government in income distribution policies. The government takes no responsibility for the income, welfare and treatment of its staff. The club's various kinds of interests are linked to the market and interest distribution is closely combined with market mechanism.

\subsection{To Establish a Professional Football League}

The establishment of China's socialist market economy system is to reform government institutions, transform government functions and to play the macro-control role effectively. Its core is to transform from department management to industry management, from direct management to macro management. Meanwhile, after the transformation from department management to industry management, the country requires adjusting various market activities by industry association. And through making up contracts, and constraining the marketing activities of members, the league will play its unique role in maintaining market order and fair competition.

The professional football clubs is an organization which holds sports competitions of high levels, and develops training competition and its related products. Club only takes the market as the guidance and satisfies the needs of society to the maximum to obtain good economic benefits and sustainable development. Because the professional football clubs need more operators to provide economy, common performance and related services, common interests' spokesperson will be needed to establish, that is league union (industry association in the real meaning). However Chinese football association of the current management is actually the authorities, whose client is all the people. But the client is difficult to perform the effective supervision to the football association. So the football association will become the "dictator" to a large extent. Once the right enters the market, the market trading will no longer be equal. To solve this problem, we should establish a real sense of industry association (football league) as the club's common agents, who coordinate league affairs instead of club, adjust the disputes among clubs, punish irregularities and maintain the fairness and vitality of the league. But as for when to build the league union, immediately or the time when the domestic market can attract enough private capital, state-owned club is out of the league and the Chinese football association completes functional change, this problem is needed to discuss.

\subsection{To Set Up the Brand Consciousness and Mold Brand Connotation}

The club management should set up modern brand consciousness as soon as possible, pay more attention to the club's brand and have a clear plan for brand strategy. Investors should always think about club brand image in making a critical decision and regard the club's brand as the precious wealth like tangible assets.

The club brand development planning is a long-term business basic plan from the angle of the market. Whether the planning is scientific or conformed to the facts is related directly to the club brand's prosperity and success or failure of it. The key to club brand positioning should pay attention to the emotion. Keeping a good emotion, there needs to consider the characteristics of the club itself, such as geography, history accumulation and the club's human resources. As for tangible resources, try to make a difference in brand personality style from other clubs.

The connotation of the brand decided the brand management and supported the brand development, which is not only the effective transmission of club concept, but also the brand logo different from others. Therefore, brand management can't ignore the connotation and the special club culture should be input in the club brand currently in order to improve the grade of the club brand, reveal the characteristics of club brand and promote the value of the club brand. 


\section{Suggestions}

\subsection{To Form a Football Leadership}

As is known to all, the football association leaders are seldom acted by football players, mostly assigned by the state general administration of sports, however, who are not sports majored, including middle-level leaders. The management by an outsider could definitely influence the development of China's football schedule. The author believes that Chinese professional football development will increase quickly if the leaders are reelected and acted by those who received advanced education in foreign countries.

\subsection{To Build Players Union}

In the operation of Chinese professional football clubs, players have been vulnerable groups, sometimes even weaker than migrant workers, whose survival is crippled, so that if the players are in the poor condition, they will be suspected and criticized by the team management. Wage bonus is often delayed into the next year. It is helpful to establish the players union and maintain their interests and safeguard their rights. To pay players' wages on time can not only guarantee their own interests, but China football professional league level also will make progress.

\subsection{To Develop Related Market Products}

Compared to the foreign advanced professional league, the development of related products is to be improved in our professional league, which has developed for many years. In the foreign countries, when the competition is coming, the fans would participate like joining in a big holiday and buy a series of souvenirs such as jersey, hat, scarf etc in the fans shop. However, in China, the fans only watch the game and there are no fans shops to provide souvenirs. Now only a few clubs like Shandong Luneng, Guangzhou Hengda, Shanghai Shenhua, etc had a small amount of fans development in china football association super league.

\section{Conclusion}

Based on the above analysis, the writer thinks that it is necessary to hold the reform for the operation and management of current professional football clubs. Or the development of Chinese professional football clubs will be seriously influenced.

\section{References}

Li, Ling. (2009). The Problems and the Countermeasure Analysis of the Management in Chinese Professional Football Clubs. Sports World, (9), 26- 27.

Wan, Guohua. (2006). Analysis of Soccer Club's Difficulties. Entrepreneurs: Part of Theory, (5), 153-154.

Wang, Songyan, \& Cai, Yan. (2005). the Analysis of the Present Situation of Chinese Professional Football Club's Development. Hubei Sports Science and Technology, (4), 427-429. 